\title{
Using Metric Distance Ranking Method to Find Intuitionistic Fuzzy Critical Path
}

\author{
P. Jayagowri ${ }^{1}$ and G. Geetharamani ${ }^{2}$ \\ ${ }^{1}$ Department of Mathematics, Sudharsan Engineering College, Tamil Nadu 622501, India \\ ${ }^{2}$ Department of Mathematics, Anna University Chennai, BIT Campus, Tamil Nadu 620024, India \\ Correspondence should be addressed to P. Jayagowri; jaya.gowri@ymail.com
}

Received 1 April 2015; Revised 4 June 2015; Accepted 28 June 2015

Academic Editor: Humberto Bustince

Copyright (C) 2015 P. Jayagowri and G. Geetharamani. This is an open access article distributed under the Creative Commons Attribution License, which permits unrestricted use, distribution, and reproduction in any medium, provided the original work is properly cited.

\begin{abstract}
Network analysis is a technique which determines the various sequences of activities concerning a project and the project completion time. The popular methods of this technique which is widely used are the critical path method and program evaluation and review techniques. The aim of this paper is to present an analytical method for measuring the criticality in an (Atanassov) intuitionistic fuzzy project network. Vague parameters in the project network are represented by (Atanassov) intuitionistic trapezoidal fuzzy numbers. A metric distance ranking method for (Atanassov) intuitionistic fuzzy numbers to a critical path method is proposed. (Atanassov) Intuitionistic fuzzy critical length of the project network is found without converting the (Atanassov) intuitionistic fuzzy activity times to classical numbers. The fuzzified conversion of the problem has been discussed with the numerical example. We also apply four different ranking procedures and we compare it with metric distance ranking method. Comparison reveals that the proposed ranking method is better than other raking procedures.
\end{abstract}

\section{Introduction}

Critical path method is a network based method designed for planning and managing of complicated project in real world applications. According to the critical path, the decision maker can control the time and the cost of the project and improve the efficiency of resource allocation to ensure the project quality. In many situations, project can be complicated and challenging to manage. There are many cases where the activity times may not be presented in a precise manner. An alternative way to deal with imprecise data is to employ the concept of fuzziness by vague activity times that can be represented by fuzzy sets. Fuzzy set theory proposed by Zadeh [1] can play a significant role in solving such a management problem.

Chanas and Zielinski [2] proposed a method to make critical path analysis in the network with fuzzy activity times (interval activity times, fuzzy numbers of L-R type) by directly applying the extension principle to the usual criticality notion treated as a function of activity duration time in the network. Chanas and Kamburowski [3] explained fuzzy variables in PERT. Chen and Huang [4] proposed a new model that combines fuzzy set theory with the PERT technique to determine the critical degrees of activities and paths, latest and earliest starting time, and floats. Based on signed distance ranking of fuzzy numbers, Yao and Lin [5] found out fuzzy critical path method based on signed distance ranking method. Styeptsov and Tyshchuk [6] created a proficient method of calculation of fuzzy time windows for late start and finish times of operations in the problem of fuzzy network. Nasution [7] proposed a fuzzy critical path method by considering interactive fuzzy subtraction and by observing that only the nonnegative part of the fuzzy numbers can have physical elucidation.

Ravi Shankar et al. [8] proposed new defuzzified formula to find critical path in a fuzzy project network. Elizabeth and Sujatha $[9,10]$ introduced new ranking methods to find fuzzy critical path problem for project network.

In this paper a new algorithm is proposed to find (Atanassov) intuitionistic fuzzy critical path without converting 
the (Atanassov) intuitionistic fuzzy activity times to crisp number. Here we propose a metric distance ranking method to an (Atanassov) intuitionistic fuzzy critical path method for a project network problem. Finally we compare the proposed ranking method with existing method and conclude the paper. This paper is organized as follows. In Section 2, basic definitions of (Atanassov) intuitionistic fuzzy set theory have been reviewed and some new definitions are framed for (Atanassov) intuitionistic fuzzy critical path method. Section 3 gives new procedures to find out the (Atanassov) intuitionistic fuzzy critical path using an illustrative example. Different ranking approach has been given and results are discussed. Finally Section 4 concludes the paper.

\section{Preliminaries}

In this section some basic definitions and ranking function are reviewed. A new ranking approach is introduced for (Atanassov) intuitionistic trapezoidal fuzzy number.

Definition 1 (fuzzy set (Zadeh [1])). Let a nonempty fuzzy set $A$ in $x$ be characterized by a membership function $\mu_{A}(x)$ for all $x \in E$ which associates with each point in $E$, a real number in the interval $[0,1]$, with the value of $\mu_{A}(x)$ at $x$ representing the "grade of membership" of in $x$ in $A$.

Definition 2 (Atanassov intuitionistic fuzzy set [11]). Let $X$ be universe of discourse; then an intuitionistic fuzzy set (IFS) $A$ in $X$ is given by $A=\left\{\left(x, \mu_{A}(x), \gamma_{A}(x)\right) / x \in X\right\}$, where the functions $\mu_{A}(x): X \rightarrow[0,1]$ and $\gamma_{A}(x): X \rightarrow[0,1]$ determine the degree of membership and nonmembership of the element $x \in X$, respectively, and for every $x \in X, 0 \leq$ $\mu_{A}(x)+\gamma_{A}(x) \leq 1$.

Definition 3 (trapezoidal intuitionistic fuzzy number). An (Atanassov) intuitionistic fuzzy number $A=\left\{\left(a_{1}, a_{2}, a_{3}\right.\right.$, $\left.\left.a_{4}\right)\left(b_{1}, b_{2}, b_{3}, b_{4}\right)\right\}$ is said to be a trapezoidal (Atanassov) intuitionistic fuzzy number (see Figure 1) if its membership function and nonmembership function are given by

$$
\begin{gathered}
\mu_{A}(x)= \begin{cases}\frac{\left(x-a_{1}\right)}{\left(a_{2}-a_{1}\right)}, & a_{1} \leq x \leq a_{2} \\
1, & a_{2} \leq x \leq a_{3} \\
\frac{\left(x-a_{4}\right)}{\left(a_{3}-a_{4}\right)}, & a_{3} \leq x \leq a_{4},\end{cases} \\
\gamma_{A}(x)= \begin{cases}\frac{\left(x-b_{1}\right)}{\left(b_{2}-b_{1}\right)}, & b_{1} \leq x \leq b_{2} \\
1, & b_{2} \leq x \leq b_{3} \\
\frac{\left(x-b_{4}\right)}{\left(b_{3}-b_{4}\right)}, & b_{3} \leq x \leq b_{4} .\end{cases}
\end{gathered}
$$

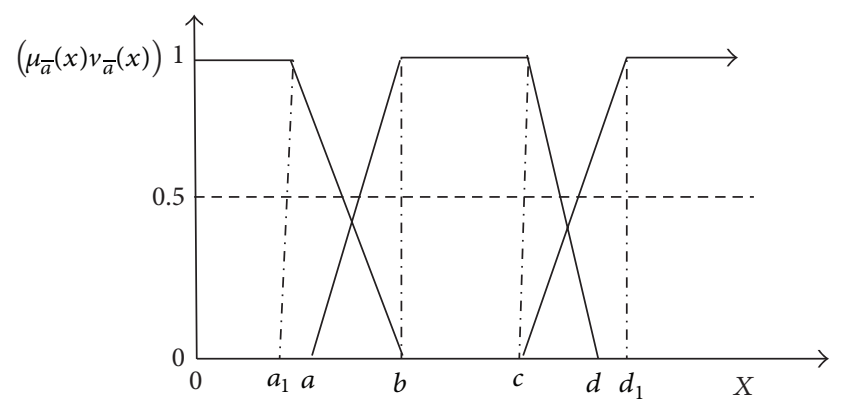

FIgURE 1: Trapezoidal intuitionistic fuzzy number.

Definition 4 (arithmetic operations of trapezoidal (Atanassov) intuitionistic fuzzy number). If $\widetilde{A}^{I}=\left\{\left(a_{1}, a_{2}, a_{3}, a_{4}\right)\right.$; $\left.\left(a_{1}^{\prime}, a_{2}^{\prime}, a_{3}^{\prime}, a_{4}^{\prime}\right)\right\}$ and $\widetilde{B}^{I}=\left\{\left(b_{1}, b_{2}, b_{3}, b_{4}\right) ;\left(b_{1}^{\prime}, b_{2}^{\prime}, b_{3}^{\prime}, b_{4}^{\prime}\right)\right\}$ are two (Atanassov) intuitionistic fuzzy numbers, we define:

\section{Addition:}

$$
\begin{gathered}
\widetilde{A}^{I}+\widetilde{B}^{I}=\left\{\left(a_{1}+b_{1}, a_{2}+b_{2}, a_{3}+b_{3}, a_{4}+b_{4}\right) ;\right. \\
\left.\left(a_{1}^{\prime}+b_{1}^{\prime}, a_{2}^{\prime}+b_{2}^{\prime}, a_{3}^{\prime}+b_{3}^{\prime}, a_{4}^{\prime}+b_{4}^{\prime}\right)\right\}
\end{gathered}
$$

Subtraction:

$$
\begin{gathered}
\widetilde{A}^{I}-\widetilde{B}^{I}=\left\{\left(a_{1}-a_{4}^{\prime}, a_{2}-a_{3}^{\prime}, a_{3}-a_{2}^{\prime}, a_{4}-a_{1}^{\prime}\right) ;\right. \\
\left.\left(b_{1}-b_{4}^{\prime}, b_{2}-b_{3}^{\prime}, b_{3}-b_{2}^{\prime}, b_{4}-b_{1}^{\prime}\right)\right\} .
\end{gathered}
$$

Definition 5 (arithmetic operations on two trapezoidal (Atanassov) intuitionistic fuzzy activity times). Let $\widetilde{\mathrm{IFAT}}_{1}=\left\{\left(a_{\mu_{1}}\right.\right.$, $\left.\left.b_{\mu_{1}}, c_{\mu_{1}}, d_{\mu_{1}}\right)\left(a_{\gamma_{1}}, b_{\gamma_{1}}, c_{\gamma_{1}}, d_{\gamma_{1}}\right)\right\}$ and $\widetilde{\mathrm{IFAT}}_{2}=\left\{\left(a_{\mu_{2}}, b_{\mu_{2}}, c_{\mu_{2}}\right.\right.$, $\left.\left.d_{\mu_{2}}\right)\left(a_{\gamma_{2}}, b_{\gamma_{2}}, c_{\gamma_{2}}, d_{\gamma_{2}}\right)\right\}$ be any two (Atanassov) intuitionistic fuzzy activity times. (i) For addition operation (+) we have the following.

Let

$$
\begin{aligned}
& \widetilde{\mathrm{IFAT}}_{1}+\widetilde{\mathrm{IFAT}}_{2}=\left\{\left(a_{\mu_{1}}, b_{\mu_{1}}, c_{\mu_{1}}, d_{\mu_{1}}\right)\right. \\
& \cdot\left(a_{\gamma_{1}}, b_{\gamma_{1}}, c_{\gamma_{1}}, d_{\gamma_{1}}\right)+\left(a_{\mu_{2}}, b_{\mu_{2}}, c_{\mu_{2}}, d_{\mu_{2}}\right) \\
& \left.\cdot\left(a_{\gamma_{2}}, b_{\gamma_{2}}, c_{\gamma_{2}}, d_{\gamma_{2}}\right)\right\} \\
& =\left\{\left(a_{\mu_{1}}+a_{\mu_{2}}, b_{\mu_{1}}+b_{\mu_{2}}, c_{\mu_{1}}+c_{\mu_{2}}, d_{\mu_{1}}+d_{\mu_{2}}\right) ;\right. \\
& \left.\left(a_{\gamma_{1}}+a_{\gamma_{2}}, b_{\gamma_{1}}+b_{\gamma_{2}}, c_{\gamma_{1}}+c_{\gamma_{2}}, d_{\gamma_{1}}+d_{\gamma_{2}}\right)\right\} .
\end{aligned}
$$


(ii) For subtraction operation (-), we have the following. Let

$$
\begin{aligned}
& {\widetilde{\mathrm{IFAT}_{1}}}_{1}-\widetilde{\mathrm{IFAT}}_{2}=\left\{\left(a_{\mu_{1}}, b_{\mu_{1}}, c_{\mu_{1}}, d_{\mu_{1}}\right)\right. \\
& \cdot\left(a_{\gamma_{1}}, b_{\gamma_{1}}, c_{\gamma_{1}}, d_{\gamma_{1}}\right)+\left(a_{\mu_{2}}, b_{\mu_{2}}, c_{\mu_{2}}, d_{\mu_{2}}\right) \\
& \left.\cdot\left(a_{\gamma_{2}}, b_{\gamma_{2}}, c_{\gamma_{2}}, d_{\gamma_{2}}\right)\right\} \\
& =\left\{\left(a_{\mu_{1}}-d_{\mu_{2}}, b_{\mu_{1}}-c_{\mu_{2}}, c_{\mu_{1}}-b_{\mu_{2}}, d_{\mu_{1}}-a_{\mu_{2}}\right) ;\right. \\
& \left.\left(a_{\gamma_{1}}-d_{\gamma_{2}}, b_{\gamma_{1}}-c_{\gamma_{2}}, c_{\gamma_{1}}-b_{\gamma_{2}}, d_{\gamma_{1}}-a_{\gamma_{2}}\right)\right\} .
\end{aligned}
$$

Definition 6 (ranking of Atanassov intuitionistic trapezoidal fuzzy number [12]). Ranking procedure was introduced by Li [13], which was based on ratio of value and ambiguity index. Li procedure was more generalized and applicability was wider, but the ratio ranking method lacks in linearity property. For ratio ranking method,

$$
R(\widetilde{a}+\widetilde{b}, \lambda) \neq R(\widetilde{a}, \lambda)+R(\widetilde{b}, \lambda) .
$$

De and Das [14] tried to rectify this by taking linear sum of value and ambiguity indices using the following definition.

Definition 7 (see [14]). Let $\tilde{a}=\left\{\left(a_{1}, a_{2}, a_{3}, a_{4}\right) w_{\tilde{a}}, u_{\tilde{a}}\right\}$ be a trapezoidal (Atanassov) intuitionistic fuzzy number. A value index and ambiguity index for the trapezoidal (Atanassov) intuitionistic fuzzy number $\tilde{a}$ are defined as follows:

$$
\begin{aligned}
& V(\widetilde{a}, \lambda)=V_{\mu}(\widetilde{a})+\lambda\left(V_{\gamma}(\widetilde{a})-V_{\mu}(\widetilde{a})\right), \\
& A(\widetilde{a}, \lambda)=A_{\gamma}(\widetilde{a})+\lambda\left(A_{\gamma}(\widetilde{a})-A_{\mu}(\widetilde{a})\right),
\end{aligned}
$$

respectively, where $\lambda \in[0,1]$ is a weight which represents the decision maker's preference information. Limited to the above formulation, the choice $\lambda=1 / 2$ appears to be a reasonable one. One can choose $\lambda$ according to the suitability of the subject. $\lambda \in[0,1 / 2)$ indicates decision maker's pessimistic attitude towards uncertainty while $\lambda \epsilon$ $(1 / 2,1]$ indicates decision maker's optimistic attitude towards uncertainty.

With our choice $\lambda=1 / 2$, the value and ambiguity indices for trapezoidal (Atanassov) intuitionistic fuzzy number reduce to the following:

$$
\begin{aligned}
& V\left(\tilde{a}, \frac{1}{2}\right)=\frac{V_{\mu}(\widetilde{a})+V_{\gamma}(\widetilde{a})}{2}, \\
& A\left(\tilde{a}, \frac{1}{2}\right)=\frac{A_{\mu}(\tilde{a})+A_{\gamma}(\tilde{a})}{2} .
\end{aligned}
$$

The proposed ranking method is as follows:

$$
R(\widetilde{a})=V\left(\widetilde{a}, \frac{1}{2}\right)+A\left(\widetilde{a}, \frac{1}{2}\right) .
$$

Definition 8 (see [12]). Now let $A_{\alpha}$ and $A_{\beta}$ be any $\alpha$-cut and $\beta$-cut set of an trapezoidal (Atanassov) intuitionistic fuzzy number $\widetilde{A}=\left\{\left(a_{1}, b_{1}, c_{1}, d_{1}\right)\left(a_{1}^{\prime}, b_{1}^{\prime}, c_{1}^{\prime}, d_{1}^{\prime}\right)\right\}$, respectively.
Then the values of the membership and nonmembership function for the trapezoidal (Atanassov) intuitionistic fuzzy number are as follows:

$$
\begin{aligned}
V_{\mu}(A) & =\frac{a_{1}+2 b_{1}+2 c_{1}+d_{1}}{6}, \\
V_{\gamma}(A) & =\frac{b_{1}^{\prime}+c_{1}^{\prime}}{2}+\frac{d_{1}^{\prime}-c_{1}^{\prime}-b_{1}^{\prime}+a_{1}^{\prime}}{6} \\
\widetilde{A} & =\left\{\left(a_{1}, b_{1}, c_{1}, d_{1}\right)\left(a_{1}^{\prime}, b_{1}, c_{1}, d_{1}^{\prime}\right)\right\}, \\
\widetilde{B} & =\left\{\left(a_{2}, b_{2}, c_{2}, d_{2}\right)\left(a_{2}^{\prime}, b_{2}, c_{2}, d_{2}^{\prime}\right)\right\}
\end{aligned}
$$

be two trapezoidal (Atanassov) intuitionistic fuzzy number. If $a_{1}>d_{2}$ then $A>B$.

(i) If $V \mu(A)>V \mu(B)$ then $A>B$;

(ii) if $V \mu(A)<V \mu(B)$ then $A<B$;

(iii) if $V \mu(A)=V \mu(B)$ then $A$ is equivalent to $B$.

Definition 9 (Euclidean Ranking (ER) technique for trapezoidal (Atanassov) intuitionistic fuzzy numbers [10]). Let $L_{i}=\left\{\left(a_{i}, b_{i}, c_{i}, d_{i}\right)\left(a_{i}^{\prime}, b_{i}, c_{i}, d_{i}^{\prime}\right)\right\}$ be the $i$ th fuzzy path length and let $L_{\max }=\left\{(a, b, c, d)\left(a^{\prime}, b, c, d^{\prime}\right)\right\}=\left(L_{\max }, l_{\max }\right)$ be the fuzzy longest length then the Euclidean Ranking of $L_{i}$ is denoted by

$$
\begin{aligned}
& \operatorname{ER}\left(L_{i}\right)=\left(\sqrt{\left(a-a_{i}\right)^{2}+\left(b-b_{i}\right)^{2}+\left(c-c_{i}\right)^{2}+\left(d-d_{i}\right)^{2}}\right), \\
& \left(\sqrt{\left(a^{\prime}-a_{i}^{\prime}\right)^{2}+\left(b-b_{i}\right)^{2}+\left(c-c_{i}\right)^{2}+\left(d^{\prime}-d_{i}^{\prime}\right)^{2}}\right)
\end{aligned}
$$

$=($ ER of membership function; ER of nonmembership function $)$.

If $A$ and $B$ are trapezoidal (Atanassov) intuitionistic fuzzy numbers, then $A \geq B$ if and only if $\operatorname{ER}(A) \leq \operatorname{ER}(B)$.

Definition 10 (similarity ranking for trapezoidal (Atanassov) intuitionist fuzzy numbers [15]). For two (Atanassov) intuitionist fuzzy path lengths,

$$
\begin{aligned}
& \overline{L_{1}}=\left\{\left(a_{1}, b_{1}, c_{1}, d_{1}\right)\left(l_{1}, m_{1}, n_{1}, o_{1}\right)\right\}, \\
& \overline{L_{2}}=\left\{\left(a_{2}, b_{2}, c_{2}, d_{2}\right)\left(l_{2}, m_{2}, n_{2}, o_{2}\right)\right\} .
\end{aligned}
$$

For membership function,

$$
\begin{gathered}
\widetilde{L}_{\mu}^{\min }(a, b, c, d)=\min \left(L_{1}, L_{2}\right)=\left(\min \left(a_{1}, a_{2}\right),\right. \\
\left.\min \left(b_{1}, b_{2}\right), \min \left(c_{1}, c_{2}\right), \min \left(d_{1}, d_{2}\right)\right) .
\end{gathered}
$$

For nonmembership function,

$$
\begin{gathered}
\widetilde{L}_{\gamma}^{\max }(l, m, n, o)=\max \left(L_{1}, L_{2}\right)=\left(\max \left(l_{1}, l_{2}\right),\right. \\
\left.\max \left(m_{1}, m_{2}\right), \max \left(n_{1}, n_{2}\right), \max \left(o_{1}, o_{2}\right)\right) .
\end{gathered}
$$


Let $L_{i}=\left\{\left(a_{i}, b_{i}, c_{i}, d_{i}\right)\left(a_{i}^{\prime}, b_{i}, c_{i}, d_{i}^{\prime}\right)\right\}$ be the $i$ th fuzzy path length. Then the similarity ranking of trapezoidal (Atanassov) intuitionist fuzzy numbers for both membership function and nonmembership function is

$$
\begin{aligned}
& \operatorname{SD}\left(\overline{L_{i}}, \widetilde{L}_{\mu}^{\min }\right) \\
& = \begin{cases}0, & \text { if } \overline{L_{i}} \cap \widetilde{L}_{\mu}^{\min }=\varphi \\
\frac{1}{2} \frac{\left(d-a_{i}\right)^{2}}{(d-c)+\left(b_{i}-a_{i}\right)}, & \overline{L_{i}} \cap \widetilde{L}_{\mu}^{\min } \neq \varphi, \\
& \text { where } c<x<d, a_{i}<x<b_{i} \\
\frac{1}{2}\left[\left(d-a_{i}\right)+\left(c-b_{i}\right)\right], & \overline{L_{i}} \cap \widetilde{L}_{\mu}^{\min } \neq \varphi, \\
& \text { where } b_{i} \leq x \leq c,\end{cases} \\
& \operatorname{SD}\left(\overline{L_{i}}, \widetilde{L}_{\gamma}^{\max }\right) \\
& = \begin{cases}0, & \overline{L_{i}} \cap \widetilde{L}_{\gamma}^{\max }=\varphi \\
\frac{1}{2} \frac{\left(d-a_{i}\right)^{2}}{(d-c)+\left(b_{i}-a_{i}\right)}, & \overline{L_{i}} \cap \widetilde{L}_{\gamma}^{\max } \neq \varphi, \\
& \text { where } c<x<d, a_{i}<x<b_{i} \\
\frac{1}{2}\left[\left(d-a_{i}\right)+\left(c-b_{i}\right)\right], & \overline{L_{i}} \cap \widetilde{L}_{\gamma}^{\max } \neq \varphi, \\
& \text { where } b_{i} \leq x \leq c .\end{cases}
\end{aligned}
$$

Let $L_{1}$ and $L_{2}$ be two (Atanassov) intuitionistic fuzzy numbers then $L_{1}>L_{2}$ if and only if the similarity ranking of membership function of $L_{1}$ is greater than the similarity ranking of membership function of $L_{2}$ and the similarity ranking of nonmembership function of $L_{1}$ is less than the similarity ranking of nonmembership function of $L_{2}$.

Definition 11 (graded mean integration representation for trapezoidal (Atanassov) intuitionistic fuzzy number [16]). The membership and nonmembership functions of trapezoidal (Atanassov) intuitionistic fuzzy numbers are defined by Definition 3 as follows:

$$
\begin{array}{ll}
L_{\mu}(x)=\frac{x-a_{1}}{a_{2}-a_{1}} w ; & a_{1} \leq x \leq a_{2}, \\
R_{\mu}(x)=\frac{x-a_{4}}{a_{3}-a_{4}} w ; & a_{2} \leq x \leq a_{4}, \\
L_{\gamma}(x)=\frac{x-b_{1}}{b_{2}-b_{1}} w ; & b_{1} \leq x \leq b_{2}, \\
R_{\gamma}(x)=\frac{x-b_{4}}{b_{3}-b_{4}} w ; & b_{2} \leq x \leq b_{4} .
\end{array}
$$

Then $L^{-1}$ and $R^{-1}$ are inverse functions of functions $L$ and $R$, respectively. One has

$$
\begin{aligned}
& L_{\mu}^{-1}(h)=a_{1}+\frac{\left(a_{2}-a_{1}\right) h}{w}, \\
& R_{\mu}^{-1}(h)=a_{4}-\frac{\left(a_{4}-a_{3}\right) h}{w},
\end{aligned}
$$

$$
\begin{aligned}
& L_{\gamma}^{-1}(h)=b_{1}-\frac{\left(b_{1}-b_{2}\right) h}{w}, \\
& R_{\gamma}^{-1}(h)=b_{4}+\frac{\left(b_{3}-b_{4}\right) h}{w} .
\end{aligned}
$$

Then the graded mean integration representation of membership function and nonmembership function is

$$
\begin{aligned}
& P_{\mu}(A)=\frac{a_{1}+2 a_{2}+2 a_{3}+a_{4}}{6}, \\
& P_{\gamma}(A)=\frac{b_{1}+2 b_{2}+2 b_{3}+b_{4}}{6} .
\end{aligned}
$$

Let $\widetilde{A^{\prime}}=\{(a, b, c, d)(e, b, f, g)\}$ and $\widetilde{B}^{\prime}=\left\{\left(a^{\prime}, b, c, d^{\prime}\right)\left(e^{\prime}\right.\right.$, $\left.\left.b, f, g^{\prime}\right)\right\}$ be any two (Atanassov) intuitionistic triangular fuzzy numbers; then

(i) $P_{\mu}^{\alpha}\left(\widetilde{A^{\prime}}\right)<P_{\mu}^{\alpha}\left(\widetilde{B^{\prime}}\right)$ and $P_{\gamma}^{\beta}\left(\widetilde{A^{\prime}}\right)<P_{\gamma}^{\beta}\left(\widetilde{B^{\prime}}\right) \therefore \widetilde{A^{\prime}}<\widetilde{B^{\prime}}$;

(ii) $P_{\mu}^{\alpha}\left(\widetilde{A^{\prime}}\right)>P_{\mu}^{\alpha}\left(\widetilde{B^{\prime}}\right)$ and $P_{\gamma}^{\beta}\left(\widetilde{A^{\prime}}\right)>P_{\gamma}^{\beta}\left(\widetilde{B^{\prime}}\right) \therefore \widetilde{A^{\prime}}>\widetilde{B^{\prime}}$;

(iii) $P_{\mu}^{\alpha}\left(\widetilde{A^{\prime}}\right)=P_{\mu}^{\alpha}\left(\widetilde{B^{\prime}}\right)$ and $P_{\gamma}^{\beta}\left(\widetilde{A^{\prime}}\right)=P_{\gamma}^{\beta}\left(\widetilde{B^{\prime}}\right) \therefore \widetilde{A^{\prime}} \approx \widetilde{B^{\prime}}$.

Then the following ranking method is introduced in this paper.

Definition 12 (metric distance). Let $\widetilde{A}=\left\{\left(a_{1}, b_{1}, c_{1}, d_{1}\right)\right.$; $\left.\left(a_{1}^{\prime}, b_{1}, c_{1}, d_{1}^{\prime}\right)\right\}$ and $\widetilde{B}=\left\{\left(a_{2}, b_{2}, c_{2}, d_{2}\right) ;\left(a_{2}^{\prime}, b_{2}, c_{2}, d_{2}^{\prime}\right)\right\}$ be two (Atanassov) intuitionistic trapezoidal fuzzy numbers. Then the metric distance between $A$ and $B$ can be calculated as follows:

$$
\begin{aligned}
& D\left(\widetilde{A}_{\mu}, \widetilde{B}_{\mu}\right)=\left[\int_{0}^{1}\left[A_{\mu L}(\alpha)-B_{\mu L}(\alpha)\right]^{2} d \alpha\right. \\
& \left.+\int_{0}^{1}\left[A_{\mu R}(\alpha)-B_{\mu R}(\alpha)\right]^{2} d \alpha\right]^{1 / 2}, \\
& D\left(\widetilde{A}_{\gamma}, \widetilde{B}_{\gamma}\right)=\left[\int_{0}^{1}\left[A_{\gamma L}(\alpha)-B_{\gamma L}(\alpha)\right]^{2} d \alpha\right. \\
& \left.\quad+\int_{0}^{1}\left[A_{\gamma R}(\alpha)-B_{\gamma R}(\alpha)\right]^{2} d \alpha\right]^{1 / 2},
\end{aligned}
$$

where $A_{\mu L}(\alpha), B_{\mu L}(\alpha), A_{\mu R}(\alpha)$, and $B_{\mu R}(\alpha)$ are $\alpha$-cut intervals of membership function of $\widetilde{A}$ and $\widetilde{B}$, respectively, and $A_{\gamma L}(\alpha)$, $B_{\gamma L}(\alpha), A_{\gamma R}(\alpha)$, and $B_{\gamma R}(\alpha)$ are $\alpha$-cut intervals of nonmembership function of $\widetilde{A}$ and $\widetilde{B}$, respectively.

In order to rank (Atanassov) intuitionistic fuzzy numbers, let us take the (Atanassov) intuitionistic trapezoidal fuzzy number $\widetilde{B}=0$; then the metric distance between $\widetilde{A}$ and 0 is calculated as follows:

$$
\begin{gathered}
D\left(\widetilde{A}_{\mu}, 0\right)=\left[\int_{0}^{1}\left[A_{\mu L}(\alpha)\right]^{2} d \alpha\right. \\
\left.+\int_{0}^{1}\left[A_{\mu R}(\alpha)\right]^{2} d \alpha\right]^{1 / 2}
\end{gathered}
$$




$$
\begin{aligned}
& =\left[\int_{0}^{1}\left[a_{1}+\left(b_{1}-a_{1}\right) \alpha\right]^{2} d \alpha\right. \\
& \left.+\int_{0}^{1}\left[d_{1}-\left(d_{1}-c_{1}\right) \alpha\right]^{2} d \alpha\right]^{1 / 2} \\
& =\left[\frac{a_{1}^{2}+b_{1}^{2}+c_{1}^{2}+d_{1}^{2}-a_{1} b_{1}-c_{1} d_{1}}{3}\right]^{1 / 2}, \\
D & \left(\widetilde{A}_{\gamma}, 0\right)=\left[\int_{0}^{1}\left[A_{\gamma L}(\alpha)\right]^{2} d \alpha\right. \\
& \left.+\int_{0}^{1}\left[A_{\gamma R}(\alpha)\right]^{2} d \alpha\right]^{1 / 2} \\
& =\left[\int_{0}^{1}\left[a_{1}^{\prime}+\left(b_{1}-a_{1}^{\prime}\right) \alpha\right]^{2} d \alpha\right. \\
& \left.+\int_{0}^{1}\left[d_{1}^{\prime}-\left(d_{1}^{\prime}-c_{1}\right) \alpha\right]^{2} d \alpha\right]^{1 / 2} \\
& =\left[\frac{a_{1}^{\prime 2}+b_{1}^{2}+c_{1}^{2}+d_{1}^{\prime 2}+a_{1}^{\prime} b_{1}+d_{1}^{\prime} c_{1}}{3}\right]^{1 / 2} .
\end{aligned}
$$

Here,

$$
\widetilde{A}>\widetilde{B} \quad \text { iff } D(\widetilde{A}, 0)>D(\widetilde{B}, 0) .
$$

\section{Calculating Intuitionistic Fuzzy Time Values and Critical Path Analysis in (Atanassov) Intuitionistic Fuzzy Project Network [17]}

An (Atanassov) intuitionistic fuzzy project network is an acyclic directed graph, where the vertices represent events, and the direct edges represent the activities to be performed in a project network. An (Atanassov) intuitionistic fuzzy project network is represented by $\widetilde{N}=\left\{\left(\widetilde{v}_{\mu}, \widetilde{v}_{\gamma}\right)\left(\widetilde{A}_{\mu}, \widetilde{A}_{\gamma}\right)\left(\widetilde{T}_{\mu}\right.\right.$, $\left.\left.\widetilde{T}_{\gamma}\right)\right\}$.

Let $\widetilde{v}=\left(\widetilde{v}_{\mu}, \widetilde{v}_{\gamma}\right)=\left\{\left(\widetilde{v}_{\mu 1}, \widetilde{v}_{\mu 2}, \ldots, \widetilde{v}_{\mu n}\right)\left(\widetilde{v}_{\gamma 1}, \widetilde{v}_{\gamma 2}, \ldots, \widetilde{v}_{\gamma n}\right)\right\}$ be the set of (Atanassov) intuitionistic fuzzy vertices, where $\left(\widetilde{v}_{\mu 1}, \widetilde{v}_{\gamma 1}\right)$ and $\left(\widetilde{v}_{\mu n}, \widetilde{v}_{\gamma n}\right)$ are the tail and head events of the project, and each $\left(\widetilde{v}_{\mu i}, \widetilde{v}_{\gamma i}\right)$ belongs to some path from $\left(\widetilde{v}_{\mu 1}, \widetilde{v}_{\gamma 1}\right)$ to $\left(\widetilde{v}_{\mu n}, \widetilde{v}_{\gamma n}\right)$. Let $\widetilde{A} \subset \widetilde{V} \times \widetilde{V}$ be the set of a directed edge $\widetilde{A}=\left\{\left(a_{\mu i j}, a_{\gamma i j}\right)=\left(v_{\mu i}, v_{\mu j}\right)\left(v_{\gamma i}, v_{\gamma j}\right) /\right.$ for $v_{\mu i}, v_{\mu j}, v_{\gamma i}$, $\left.v_{\gamma j} \in \widetilde{V}\right\}$ that represents the activities to be performed in the project. Activity $\left(\widetilde{a}_{\mu i j}, \widetilde{a}_{\gamma i j}\right)$ is then represented by one and only one arrow with tail event $\left(\widetilde{v}_{\mu i}, \widetilde{v}_{p i}\right)$ and a head event $\left(\widetilde{v}_{\mu j}, \widetilde{v}_{\gamma j}\right)$. For each activity $\left(\widetilde{a}_{\mu i j}, \widetilde{a}_{\gamma i j}\right)$, an (Atanassov) intuitionistic fuzzy number $\widetilde{t}_{i j} \in \widetilde{T}$ is defined as the (Atanassov) intuitionistic fuzzy time required for the completion of $\left(\widetilde{a}_{\mu i j}, \widetilde{a}_{\gamma i j}\right)$. A critical path is the longest path from the initial event $\left(\widetilde{v}_{\mu 1}, \widetilde{v}_{\gamma 1}\right)$ to the terminal event $\left(\widetilde{v}_{\mu n}, \widetilde{v}_{\gamma n}\right)$ of the project network, and an activity $\left(\widetilde{a}_{\mu i j}, \widetilde{a}_{\gamma i j}\right)$ on a critical path is called a critical activity.
3.1. Notations. The notations that will be used throughout the paper are

$N$ : the set of all nodes in a project network,

EST: earliest starting time,

$\widetilde{A}_{\mu i j}$ : the activity between nodes $i$ and $j$ for membership function,

$\widetilde{A}_{\gamma i j}$ : the activity between nodes $i$ and $j$ for nonmembership function,

$\widetilde{\mathrm{IFET}}_{\mu i j}$ : (Atanassov) intuitionistic fuzzy activity time for membership function,

$\widetilde{\mathrm{IFET}}_{\gamma i j}$ : (Atanassov) intuitionistic fuzzy activity time for nonmembership function,

$\widetilde{\mathrm{IFES}}_{\mu j}$ : the earliest starting (Atanassov) intuitionistic fuzzy time for membership function of node $j$,

$\widetilde{\mathrm{IFES}}_{\gamma j}$ : the earliest starting (Atanassov) intuitionistic fuzzy time for nonmembership function of node $j$,

$\widetilde{\mathrm{IFLF}}_{\mu i}$ : the latest finishing (Atanassov) intuitionistic fuzzy time for membership function of node $i$,

$\widetilde{\mathrm{IFLF}}_{\gamma i}$ : the latest finishing (Atanassov) intuitionistic fuzzy time for nonmembership function of node $i$,

$\widetilde{\mathrm{IFTS}}_{\mu i j}$ : the total slack (Atanassov) intuitionistic fuzzy time of $\widetilde{A}_{\mu i j}$,

$\widetilde{\mathrm{IFTS}}_{\gamma i}$ : the total slack (Atanassov) intuitionistic fuzzy time of $\widetilde{A}_{\gamma i j}$,

$P_{k}$ : the $k$ th (Atanassov) intuitionistic fuzzy path,

TF: total float,

IFCPM $\left(P_{k}\right)$ : the total slack (Atanassov) intuitionistic fuzzy time of path $P_{k}$ in a project network,

$T_{i j}$ : the (Atanassov) intuitionistic fuzzy activity time.

Property 1 (forward pass calculation). Forward pass calculations are employed to calculate the earliest starting time (EST) in the project network. Set the initial node to zero for starting, that is, $\widetilde{\mathrm{IFES}}_{\mu 1}=(0,0,0,0)$ and $\widetilde{\mathrm{IFES}}_{\gamma 1}=(0,0,0,0)$,

$$
\begin{aligned}
\widetilde{\mathrm{IFES}}_{\mu j} & =\underset{i}{\operatorname{Max}}\left[\widetilde{\mathrm{IFES}}_{\mu i}(+) \widetilde{\mathrm{FET}}_{\mu i j}\right], \\
i & =\text { number of preceding nodes, } j \neq 1, j \in N, \\
\widetilde{\mathrm{IFES}}_{\gamma j} & =\operatorname{Min}_{i}\left[\widetilde{\mathrm{IFES}}_{\gamma i}(+) \widetilde{\mathrm{FET}}_{\gamma i j}\right], \\
i & =\text { number of preceding nodes, } j \neq 1, j \in N .
\end{aligned}
$$

Ranking value is utilized to identify the maximum and minimum value. 
Earliest finishing time for membership function is

$$
\begin{aligned}
& \widetilde{\mathrm{IFET}}_{\mu i j}=\text { [earliest starting intuitionistic fuzzy time for membership function } \\
& + \text { (Atanassov) intuitionistic fuzzy activity time }]
\end{aligned}
$$

Earliest finishing time for nonmembership function is

$$
\begin{aligned}
& \widetilde{\text { IFET }}_{\gamma i j}=\text { [earliest starting intuitionistic fuzzy time for nonmembership function } \\
& + \text { (Atanassov) intuitionistic fuzzy activity time }] \text {. }
\end{aligned}
$$

Property 2 (backward pass calculation). Backward pass calculations are employed to calculate the latest finishing time (LFT) in the project network. Set $\widetilde{\mathrm{IFLF}}_{\mu n}=\widetilde{\mathrm{IFES}}_{\mu n}$ and $\widetilde{\mathrm{IFLF}}_{\gamma n}=\widetilde{\mathrm{IFES}}_{\gamma n}$. One has

$$
\begin{aligned}
\widetilde{\operatorname{IFLF}}_{\mu i} & =\underset{j}{\operatorname{Min}}\left[\widetilde{\operatorname{IFLF}}_{\mu j}(-) \widetilde{\operatorname{IFET}}_{\mu i j}\right], \\
i & \neq n, i \in N, j=\text { number of succeeding nodes, }
\end{aligned}
$$

$$
\begin{aligned}
\widetilde{\mathrm{IFLF}}_{\gamma i} & =\operatorname{Max}_{j}\left[\widetilde{\operatorname{IFLF}}_{\gamma j}(-) \widetilde{\operatorname{IFET}}_{\gamma i j}\right] \\
i & \neq n, i \in N, j=\text { number of succeeding nodes. }
\end{aligned}
$$

Ranking value is utilized to identify the maximum and minimum value.

Latest starting time for membership function is

$$
\widetilde{\mathrm{IFLS}}_{\mu i j}=[\text { latest finishing intuitionistic fuzzy time for membership function (-) }
$$

(Atanassov) intuitionistic fuzzy activity time] .

Latest finishing time for nonmembership function is

$$
\begin{aligned}
& \widetilde{\mathrm{IFLS}}_{\gamma i j}=\text { [latest finishing intuitionistic fuzzy time for nonmembership function (-) (Atanassov) } \\
& \text { intuitionistic fuzzy activity time]. }
\end{aligned}
$$

Property 3 (total float (TF)). For the activity $\left(\widetilde{A}_{\mu i j}, \widetilde{A}_{\gamma i j}\right), i<$ $j$, total (Atanassov) intuitionistic fuzzy slack is

$$
\begin{gathered}
\widetilde{\operatorname{IFTS}}_{\mu i j}=\widetilde{\operatorname{IFLF}}_{\mu j}(-)\left(\widetilde{\operatorname{IFES}}_{\mu i}(+) \widetilde{\operatorname{IFET}}_{\mu i j}\right) \\
\text { or }\left(\widetilde{\operatorname{IFLF}}_{\mu j}(-) \widetilde{\operatorname{IFES}}_{\mu i}(-) \widetilde{\operatorname{IFET}}_{\mu i j}\right), \\
\widetilde{\operatorname{IFTS}}_{\gamma i j}=\widetilde{\operatorname{IFES}}_{\gamma i}(-)\left(\widetilde{\operatorname{IFLF}}_{\gamma j}(+) \widetilde{\operatorname{IFET}}_{\gamma i j}\right) \\
\text { or }\left(\widetilde{\operatorname{IFES}}_{\gamma i}(-) \widetilde{\operatorname{IFLF}}_{\gamma j}(-) \widetilde{\operatorname{IFET}}_{\gamma i j}\right), \\
1 \leq i<j \leq n ; i, j \in N .
\end{gathered}
$$

Property 4. Consider

$$
\operatorname{IFCPM}\left(p_{\mu k}\right)=\sum_{\substack{1 \leq i<j \leq n \\ i, j \in P_{\mu k}}} \widetilde{\operatorname{IFTS}}_{\mu i j} p_{\mu k} \in P,
$$

$$
\operatorname{IFCPM}\left(p_{\gamma k}\right)=\sum_{\substack{1 \leq i<j \leq n \\ i, j \in P_{\gamma k}}} \widetilde{\operatorname{IFTS}}_{\gamma i j} p_{\gamma k} \in P
$$

$P_{\mu k}$ and $P_{\gamma k}$ are the possible paths of membership function and nonmembership function, respectively, in a network changing the path from source node to the destination node, $k=1$ to $m$.

Property 5. In a project network, a path $p_{c}$ is formed such that

$$
\operatorname{IFCPM}\left(p_{c}\right)
$$

$$
=\max \left\{\frac{\operatorname{IFCPM}\left(p_{\mu k}, p_{\gamma k}\right)}{p_{\mu k}}, p_{\gamma k} \in P, k=1 \text { to } m\right\}
$$




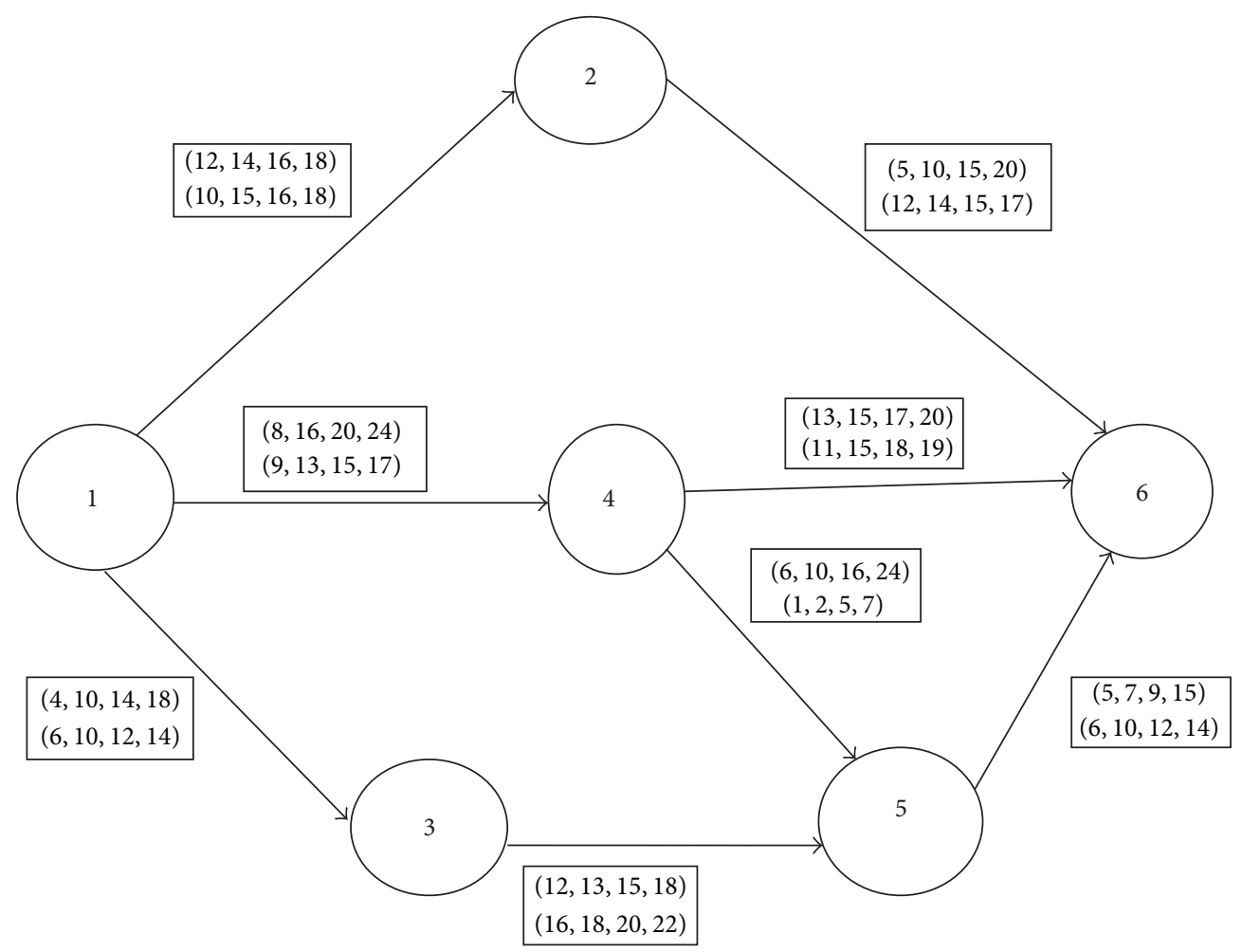

FIgURE 2: Illustrative example.

is an (Atanassov) intuitionistic fuzzy critical path. The (Atanassov) intuitionistic fuzzy critical path length is the sum of the (Atanassov) intuitionistic fuzzy activity time of the corresponding path $p_{c}$.

3.2. A New Algorithm for (Atanassov) Intuitionistic Fuzzy Critical Path. In this section, a new algorithm is proposed for finding the (Atanassov) intuitionistic fuzzy critical path. The proposed algorithm has been given as follows.

\section{Algorithm for (Atanassov) Intuitionistic Fuzzy Critical Path}

(1) Construct a project network $G(V, E)$,

(2) estimate the (Atanassov) intuitionistic fuzzy activity time,

(3) let $\widetilde{\mathrm{IFES}}_{\mu 1}=(0,0,0,0)$ and $\widetilde{\mathrm{IFES}}_{\gamma 1}=(0,0,0,0)$,

(4) calculate $\widetilde{\mathrm{IFES}}_{\mu j}$ and $\widetilde{\mathrm{IFES}}_{\gamma j}$,

(5) let $\widetilde{\mathrm{IFLF}}_{\mu n}=\widetilde{\mathrm{IFES}}_{\mu n}$ and $\widetilde{\mathrm{IFLF}}_{\gamma n}=\widetilde{\mathrm{IFES}}_{\gamma n}$,

(6) calculate $\widetilde{\mathrm{IFLF}}_{\mu i}$ and $\widetilde{\mathrm{IFLF}}_{\gamma i}$,

(7) calculate $\widetilde{\mathrm{IFTS}}_{\mu i j}$ and $\widetilde{\mathrm{IFTS}}_{\gamma i j}$

(8) find all the possible paths,

(9) calculate $\operatorname{IFCPM}\left(P_{\mu k}\right)$ and $\operatorname{IFCPM}\left(P_{\gamma k}\right)$,

(10) identify the (Atanassov) intuitionistic fuzzy critical path.
3.3. Numerical Example. In this section, (Atanassov) intuitionistic fuzzy project network problems are presented to demonstrate the computational process of (Atanassov) intuitionistic fuzzy critical path analysis proposed above.

Example 1. Consider the following.

Step 1. Suppose that there is a project network with the set of (Atanassov) intuitionistic fuzzy events

$\widetilde{V}=\{1,2,3,4,5,6\}$ shown in Figure 2, where each arc length is represented as a trapezoidal (Atanassov) intuitionistic fuzzy number. In a boiler overhauling project following activities are to be performed. Activity, description, and activity duration are in Table 1.

Step 2. See Table 1.

Step 3. Let us take the earliest starting (Atanassov) intuitionistic fuzzy times which are $\widetilde{\mathrm{IFES}}_{\mu 1}$ and $\widetilde{\mathrm{IFES}}_{\gamma 1}$.

Membership function is as follows.

Let

$$
\widetilde{\mathrm{IFES}}_{\mu 1}=(0,0,0,0)
$$

Nonmembership function is

$$
\widetilde{\mathrm{IFES}}_{\gamma 1}=(0,0,0,0)
$$

Step 4. The earliest starting (Atanassov) intuitionistic fuzzy times are as follows. 
TABLE 1: Activity duration of each activity in an (Atanassov) intuitionistic fuzzy project network.

\begin{tabular}{lcc}
\hline Activity $A_{i j}$ & Description & (Atanassov) Intuitionistic fuzzy activity duration \\
\hline $1-2$ & $\begin{array}{c}\text { Inspection of boiler by boiler engineer and } \\
\text { preparation of list of parts to be replaced } \\
\text { Placing the order and purchasing }\end{array}$ & $(12,14,16,18) ;(10,15,16,18)$ \\
$1-3$ & Dismantling of the defective parts from the boiler & $(4,10,14,18) ;(6,10,12,14)$ \\
$1-4$ & Preparation of necessary instruction for repairs & $(8,16,20,24) ;(9,13,15,17)$ \\
$2-6$ & Repairing parts in the workshop & $(5,10,15,20) ;(12,14,15,17)$ \\
$3-5$ & Installation of the repaired parts & $(12,13,15,18) ;(16,18,20,22)$ \\
$4-5$ & Inspection & $(6,10,16,24) ;(1,2,5,7)$ \\
$4-6$ & Trail run & $(13,15,17,20) ;(11,15,18,19)$ \\
$5-6$ & & $(5,7,9,15) ;(6,10,12,14)$ \\
\hline
\end{tabular}

For membership function,

$$
\begin{aligned}
& \widetilde{\mathrm{IFES}}_{\mu 2}=(12,14,16,18), \\
& \widetilde{\mathrm{IFES}}_{\mu 3}=(4,10,14,18), \\
& \widetilde{\mathrm{IFES}}_{\mu 4}=(8,16,20,24), \\
& \widetilde{\mathrm{IFES}}_{\mu 5}=\max \{(16,23,29,36) ;(14,26,36,48)\} \\
& \quad=(14,26,36,48), \\
& \widetilde{\mathrm{IFES}}_{\mu 6}=\max \{(17,24,31,38) ;(21,31,37,44) ; \\
& \quad(19,33,45,63)\}=(19,33,45,63) .
\end{aligned}
$$

For nonmembership fumction,

$$
\begin{aligned}
& \widetilde{\mathrm{IFES}}_{\gamma 2}=(10,15,16,18)=(10,15,16,18), \\
& \widetilde{\mathrm{IFES}}_{\gamma 3}=(6,10,12,14)=(6,10,12,14), \\
& \widetilde{\mathrm{IFES}}_{\gamma 4}=(9,13,15,17), \\
& \widetilde{\mathrm{IFES}}_{\gamma 5}=\min \{(22,28,32,36) ;(10,15,20,24)\} \\
& \quad=(10,15,20,24), \\
& \widetilde{\mathrm{IFES}}_{\gamma 6}=\min \{(20,28,33,36) ;(22,29,31,35) ; \\
& \quad(16,25,32,38)\}=(16,25,32,38) .
\end{aligned}
$$

Step 5. Let us take the latest finishing (Atanassov) intuitionistic fuzzy time as follows.

Membership function is

$$
\widetilde{\mathrm{IFLF}}_{\mu n}=\widetilde{\mathrm{IFES}}_{\mu n}
$$

Nonmembership function is

$$
\widetilde{\mathrm{IFLF}}_{\gamma n}=\widetilde{\mathrm{IFES}}_{\gamma n} \text {. }
$$

Step 6. The latest finishing (Atanassov) intuitionistic fuzzy times are as follows.
For membership function, we have the following. Here,

$$
\begin{aligned}
& \widetilde{\operatorname{IFLF}}_{\mu 6}=\widetilde{\operatorname{IFES}}_{\mu 6}=(19,33,45,63), \\
& \widetilde{\operatorname{IFLF}}_{\mu 5}=(19,33,45,63)-(5,7,9,15) \\
& \quad=(4,24,38,58), \\
& \widetilde{\operatorname{IFLF}}_{\mu 4}=\min \{(-20,8,28,52) ;(-1,16,30,50)\} \\
& \quad=(-20,8,28,52), \\
& \widetilde{\operatorname{IFLF}}_{\mu 3}=(-14,9,25,46), \\
& \widetilde{\operatorname{IFLF}}_{\mu 2}=(-1,18,35,58), \\
& \widetilde{\operatorname{IFLF}}_{\mu 1}=\min \{(-19,2,24,46) ;(-44,-12,12,44) ; \\
& \quad(-32,-5,15,42)\}=(-44,-12,12,44) .
\end{aligned}
$$

For nonmembership function,

$$
\begin{aligned}
& \widetilde{\mathrm{IFLF}}_{\gamma 6}=\widetilde{\mathrm{IFES}}_{\gamma 6}=(16,25,32,38), \\
& \widetilde{\mathrm{IFLF}}_{\gamma 5}=(2,13,22,32), \\
& \quad=(-5,8,20,31), \\
& \widetilde{\mathrm{IFLF}}_{\gamma 4}=\max \{(-3,7,17,27) ;(-5,8,20,31)\} \\
& \widetilde{\mathrm{IFLF}}_{\gamma 3}=(-20,-7,4,16), \\
& \widetilde{\mathrm{IFLF}}_{\gamma 2}=(-1,10,18,26), \\
& \quad \cdot(-34,-19,-6,10)\}=(-22,-7,7,22) .
\end{aligned}
$$

Step 7. Tables 2 and 3 described how to determine $\widetilde{\mathrm{IFTS}}_{\mu i j}$ and $\widetilde{\mathrm{IFTS}}_{\gamma i j}$. 
TABLE 2: Total slack (Atanassov) intuitionistic fuzzy time for each activity in an (Atanassov) intuitionistic fuzzy project network and critical path for membership function.

\begin{tabular}{|c|c|c|c|c|}
\hline $\begin{array}{l}\text { Activity }(i-j) \\
i<j\end{array}$ & Duration $\widetilde{\mathrm{IFET}}_{\mu i j}$ & $\widetilde{\mathrm{IFES}}_{\mu i}$ & $\widetilde{\mathrm{IFLF}}_{\mu j}$ & $\widetilde{\mathrm{IFTS}}_{\mu i j}$ \\
\hline $1-2$ & $(12,14,16,18)$ & $(0,0,0,0)$ & $(-1,18,35,58)$ & $(-38,-12,12,38)$ \\
\hline $1-3$ & $(4,10,14,18)$ & $(0,0,0,0)$ & $(-14,9,25,46)$ & $(-28,-2,19,44)$ \\
\hline $1-4$ & $(8,16,20,24)$ & $(0,0,0,0)$ & $(-20,8,28,52)$ & $(-17,5,25,45)$ \\
\hline $2-6$ & $(5,10,15,20)$ & $(12,14,16,18)$ & $(19,33,45,63)$ & $(-38,-12,12,38)$ \\
\hline $3-5$ & $(12,13,15,18)$ & $(4,10,14,18)$ & $(4,24,38,58)$ & $(-28,-2,19,44)$ \\
\hline $4-5$ & $(6,10,16,24)$ & $(8,16,20,24)$ & $(4,24,38,58)$ & $(-38,-12,12,38)$ \\
\hline $4-6$ & $(13,15,17,20)$ & $(8,16,20,24)$ & $(19,33,45,63)$ & $(-25,-4,14,42)$ \\
\hline $5-6$ & $(5,7,9,15)$ & $(14,26,36,48)$ & $(19,33,45,63)$ & $(-44,-12,12,44)$ \\
\hline
\end{tabular}

TABLE 3: Total slack (Atanassov) intuitionistic fuzzy time for each activity in an (Atanassov) intuitionistic fuzzy project network and critical path for nonmembership function.

\begin{tabular}{lcccc}
\hline $\begin{array}{l}\text { Activity }(i-j) \\
i<j\end{array}$ & Duration $\widetilde{\mathrm{IFET}}_{\gamma i j}$ & $\widetilde{\mathrm{IFES}}_{\gamma i}$ & $\widetilde{\mathrm{IFLF}}_{\gamma j}$ & $\widetilde{\mathrm{IFTS}}_{\gamma i j}$ \\
\hline $1-2$ & $(10,15,16,18)$ & $(10,15,16,18)$ & $(-22,-7,7,22)$ & $(-30,-8,8,30)$ \\
$1-3$ & $(6,10,12,14)$ & $(6,10,12,14)$ & $(-22,-7,7,22)$ & $(-30,-9,9,30)$ \\
$1-4$ & $(9,13,15,17)$ & $(9,13,15,17)$ & $(-22,-7,7,22)$ & $(-30,-9,9,30)$ \\
$2-6$ & $(12,14,15,17)$ & $(16,25,32,38)$ & $(-1,10,18,26)$ & $(-28,-1,9,28)$ \\
$3-5$ & $(16,18,20,22)$ & $(10,15,20,24)$ & $(-20,-7,4,16)$ & $(-28,-10,10,28)$ \\
$4-5$ & $(1,2,5,7)$ & $(10,15,20,24)$ & $(-5,8,20,31)$ & $(-34,-13,9,32)$ \\
$4-6$ & $(11,15,18,19)$ & $(16,25,32,38)$ & $(-5,8,20,31)$ & $(-30,-9,9,30)$ \\
$5-6$ & $(6,10,12,14)$ & $(16,25,32,38)$ & $(2,13,22,32)$ & \\
\hline
\end{tabular}

TABLE 4: The total slack (Atanassov) intuitionistic fuzzy time of path $p_{\mu k} \& p_{\gamma k}$

\begin{tabular}{lcc}
\hline All paths & $\begin{array}{c}\operatorname{IFCPM}\left(p_{\mu k}\right) k=1 \text { to } 4 \\
\text { (membership function) }\end{array}$ & $\begin{array}{c}\operatorname{IFCPM}\left(p_{\gamma k}\right) k=1 \text { to } 4 \\
\text { (nonmembership } \\
\text { function) }\end{array}$ \\
\hline $1 \rightarrow 2 \rightarrow 6$ & $(-38,4,42,92)$ & $(-57,-16,16,57)$ \\
$1 \rightarrow 4 \rightarrow 6$ & $(-69,-16,26,86)$ & $(-64,-22,18,62)$ \\
$1 \rightarrow 3 \rightarrow 5 \rightarrow 6$ & $(-108,-22,42,128)$ & $(-88,-19,27,88)$ \\
$\mathbf{1} \rightarrow \mathbf{4} \rightarrow \mathbf{5} \rightarrow \mathbf{6}$ & $(-\mathbf{1 3 2},-\mathbf{3 6}, \mathbf{3 6}, \mathbf{1 3 2})$ & $\mathbf{( - 8 8 , - 2 8 , 2 8 , 8 8 )}$ \\
\hline
\end{tabular}

Steps 8 and 9. The total slack (Atanassov) intuitionistic fuzzy time of path $p_{\mu k}$ and path $p_{\gamma k}$ in a project network is IFCPM $\left(p_{\mu k}\right)$ and IFCPM $\left(p_{\gamma k}\right)$. Find all possible paths and calculate $\operatorname{IFCPM}\left(p_{\mu k}\right)$ and IFCPM $\left(p_{\gamma k}\right)$ (Table 4$)$ by using Property 4.

Step 10. Hence the (Atanassov) intuitionistic fuzzy critical path is $1 \rightarrow 4 \rightarrow 5 \rightarrow 6$.

3.4. Different Ranking Approach. To find rank using Euclidean Distance method [10], we need $L_{\max }=(-38,4,42$, 132) from membership function $l_{\max }=(-57,-16,28,88)$ from nonmembership function using Table 4 . To find rank using similarity ranking [15], we need $\widetilde{L}_{\mu}^{\min }=(-132,-36$, 26, 86) from membership and $\widetilde{L}_{\gamma}^{\max }=(-57,-16,28,88)$ from nonmembership function using Table 4 . Then applying trapezoidal ranking method (Definition 8) and graded mean integration ranking method [18] to identify the (Atanassov) intuitionistic fuzzy critical path. Finally apply our proposed metric distance ranking method (Definition 12) which is used to identify the (Atanassov) intuitionistic fuzzy critical path. All ranking methods are mentioned in a separate table (Table 5) for membership function and Table 6 for nonmembership function.

The (Atanassov) intuitionistic fuzzy critical path is $1 \rightarrow$ $4 \rightarrow 5 \rightarrow 6$ whose critical path length is calculated as follows:

$$
\begin{aligned}
& ((8,16,20,24) ;(9,13,15,17) \\
& \quad+(6,10,16,24) ;(1,2,5,7) \\
& \quad+(5,7,9,15) ;(6,10,12,14)) \\
& \quad=((19,33,45,63) ;(16,25,32,38))
\end{aligned}
$$

The project completed time is approximately 2 months.

3.5. Results and Discussions. (Atanassov) intuitionistic fuzzy critical path and intuitionist fuzzy critical path length are useful information for the project to make decision in planning and scheduling complex projects. In this paper, metric distance ranking method is introduced to identify the (Atanassov) intuitionistic fuzzy critical path. And also we used Rezvani [12] ranking method, Euclidian Distance measure [10] similarity ranking method [15], and graded 


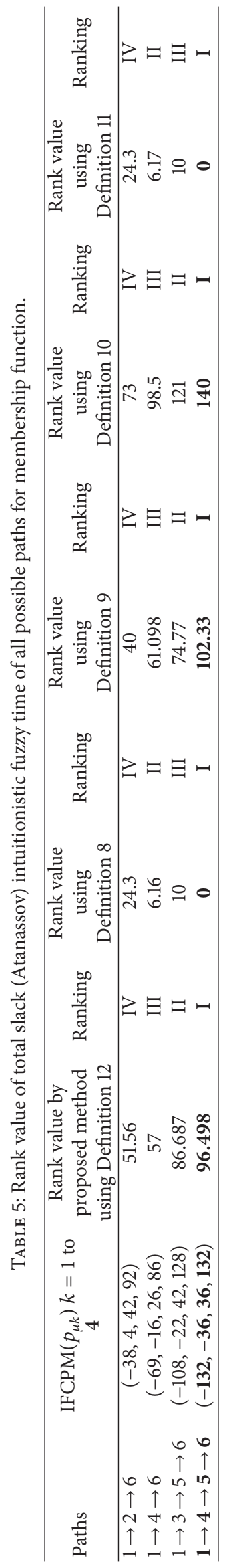




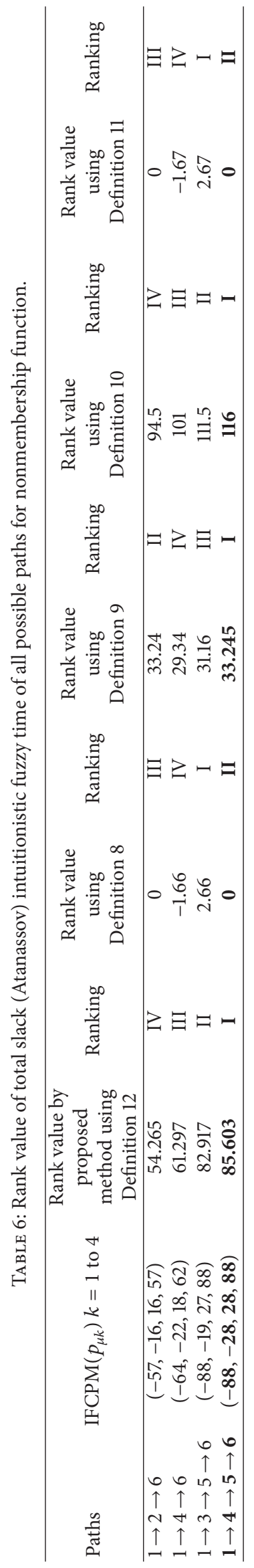


mean integration ranking method to rank the path. Using Definitions 8 and 11 of ranking methods, we cannot suitably identify the required optimal path. Using Definitions 9 and 10 , we get optimal path but compared to proposed method it is not precise. Now comparing these five ranking methods metric distance method is very effective; therefore the proposed method is very dynamic in determining the (Atanassov) intuitionistic critical path and critical path length in fuzzy sense.

\section{Conclusion}

This paper proposes an algorithm to tackle the problem in (Atanassov) intuitionistic fuzzy environment. Here a new analytical method using (Atanassov) intuitionistic trapezoidal fuzzy number for finding critical path in an (Atanassov) intuitionistic fuzzy project network has been proposed. The method proposed in this paper is more effective and easy. We have computed total (Atanassov) intuitionistic fuzzy slack time for each path in (Atanassov) intuitionistic fuzzy project network to find the critical path using metric distance ranking method. The validity of the proposed method is examined with numerical examples. It has particularly provided for explaining the proposed procedure in detail.

\section{Conflict of Interests}

The authors declare that there is no conflict of interests regarding the publication of this paper.

\section{References}

[1] L. A. Zadeh, "Fuzzy set," Information and Control, vol. 8, pp. 338-353, 1965.

[2] S. Chanas and P. Zieliński, "Critical path analysis in the network with fuzzy activity times," Fuzzy Sets and Systems, vol. 122, no. 2, pp. 195-204, 2001.

[3] S. Chanas and J. Kamburowski, "The use of fuzzy variables in PERT," Fuzzy Sets and Systems, vol. 5, no. 1, pp. 11-19, 1981.

[4] C.-T. Chen and S.-F. Huang, "Applying fuzzy method for measuring criticality in project network," Information Sciences, vol. 177, no. 12, pp. 2448-2458, 2007.

[5] J.-S. Yao and F.-T. Lin, "Fuzzy critical path method based on signed distance ranking of fuzzy numbers," IEEE Transactions on Systems, Man, and Cybernetics-Part A: Systems and Humans, vol. 30, no. 1, pp. 76-82, 2000.

[6] A. I. Slyeptsov and T. A. Tyshchuk, "Fuzzy critical path method for project network planning and control," Cybernetics and System Analysis, vol. 3, pp. 158-170, 1997.

[7] S. H. Nasution, "Fuzzy critical path method," IEEE Transactions on Systems, Man and Cybernetics, vol. 24, no. 1, pp. 48-57, 1994.

[8] N. Ravi Shankar, V. Sireesha, and P. Phani Bushan Rao, "An analytical method for finding critical path in a fuzzy project network," International Journal of Contemporary Mathematical Sciences, vol. 5, no. 20, pp. 953-962, 2010.

[9] S. Elizabeth and L. Sujatha, "Fuzzy critical path problem for project network," International Journal of Pure and Applied Mathematics, vol. 85, no. 2, pp. 223-240, 2013.
[10] S. Elizabeth and L. Sujatha, "Project scheduling method using triangular intuitionistic fuzzy numbers and triangular fuzzy numbers," Applied Mathematical Sciences, vol. 9, no. 1-4, pp. 185-198, 2015.

[11] K. T. Atanassov, "Intuitionistic fuzzy sets," Fuzzy Sets and Systems, vol. 20, no. 1, pp. 87-96, 1986.

[12] S. Rezvani, "Ranking method of trapezoidal intuitionistic fuzzy numbers," Annals of Fuzzy Mathematics and Informatics, vol. 5, no. 3, pp. 515-523, 2013.

[13] D.-F. Li, "A ratio ranking method of triangular intuitionistic fuzzy numbers and its application to MADM problems," Computers \& Mathematics with Applications, vol. 60, no. 6, pp. 1557$1570,2010$.

[14] P. K. De and D. Das, "A study on ranking of trapezoidal intuitionistic fuzzy numbers," International Journal of Computer Information Systems and Industrial Management Applications, vol. 6, pp. 437-444, 2014.

[15] P. Jayagowri and G. Geetharamani, "Using similarity degree approach for shortest path in intuitionistic fuzzy network," in Proceedings of the International Conference on Computing, Communication and Applications (ICCCA '12), pp. 1-6, IEEE, Dindigul, India, February 2012.

[16] P. Jayagowri and G. Geetharamani, "A new approach to shortest paths in intuitionistic trapezoidal fuzzy numbers," Pensee Journal, vol. 76, no. 1, pp. 22-30, 2014.

[17] P. Jayagowri and G. Geetharamani, "A critical path problem using intuitionistic trapezoidal fuzzy number," Applied Mathematical Sciences, vol. 8, no. 52, pp. 2555-2562, 2014.

[18] D. Dubois and H. Prade, Possibility Theory: an Approach to Computerized Processing of Uncertainty, Plenum Press, New York, NY, USA, 1988. 


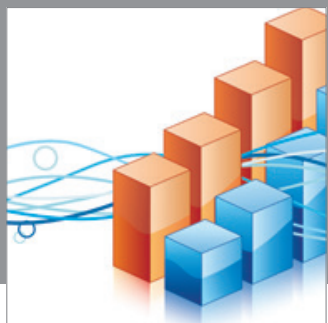

Advances in

Operations Research

mansans

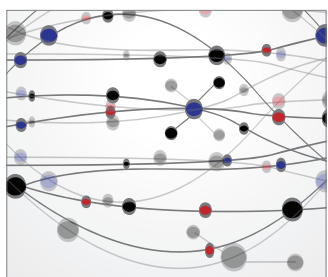

The Scientific World Journal
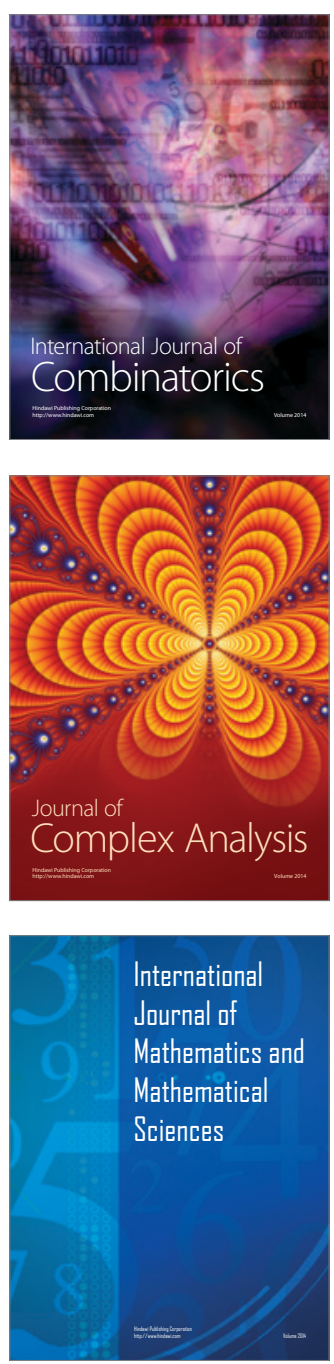
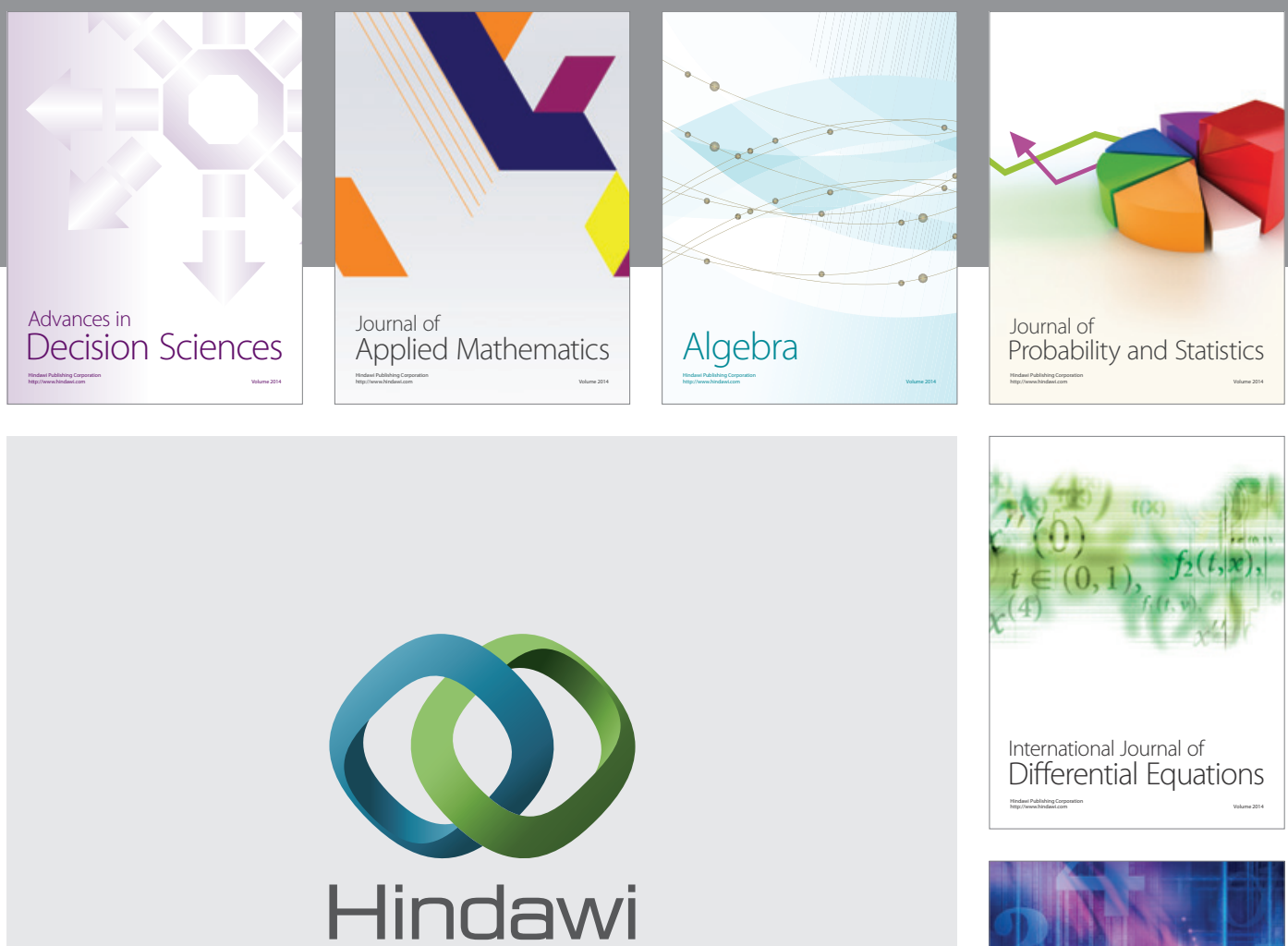

Submit your manuscripts at http://www.hindawi.com
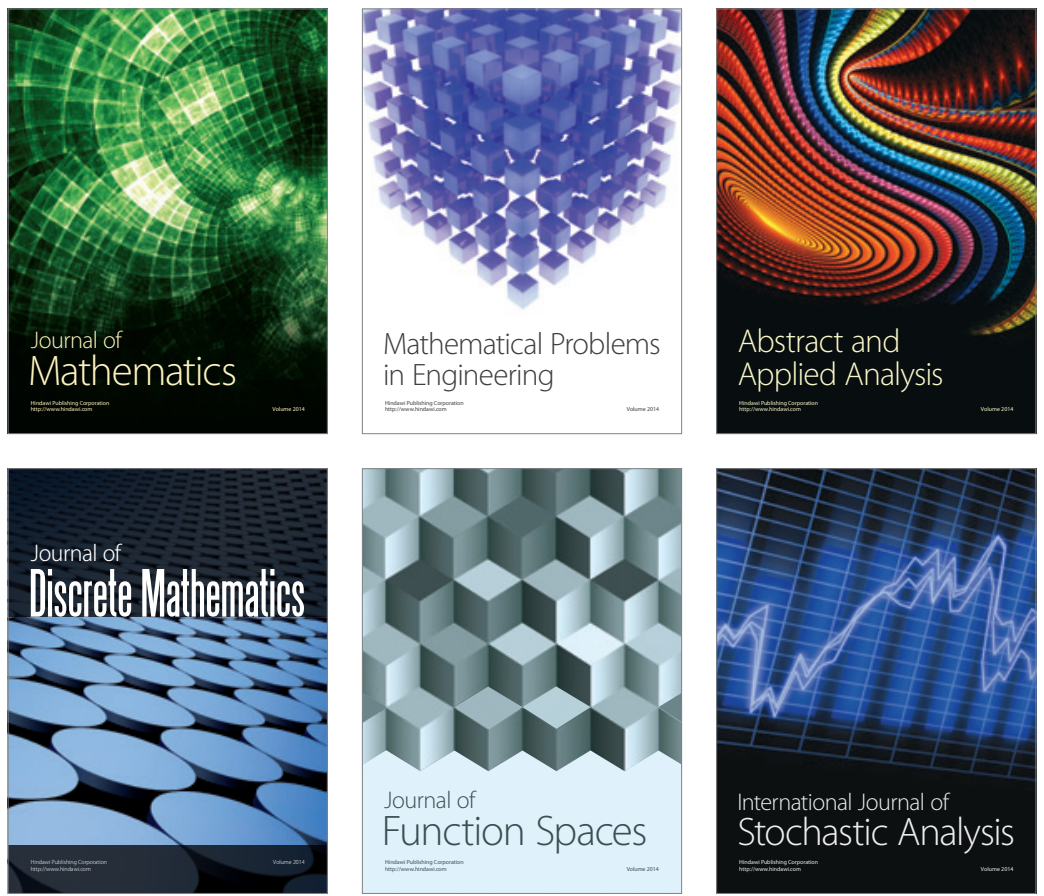

Journal of

Function Spaces

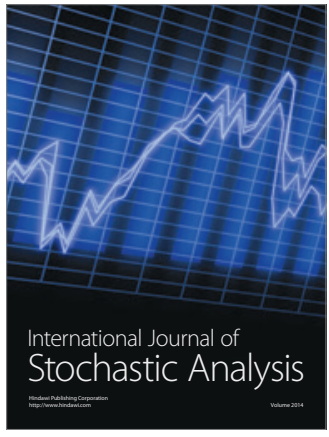

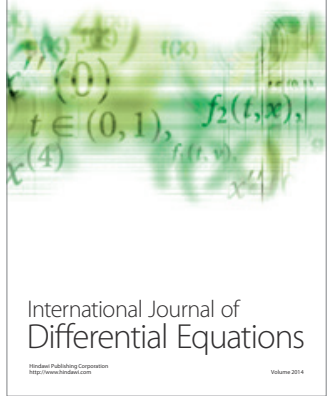
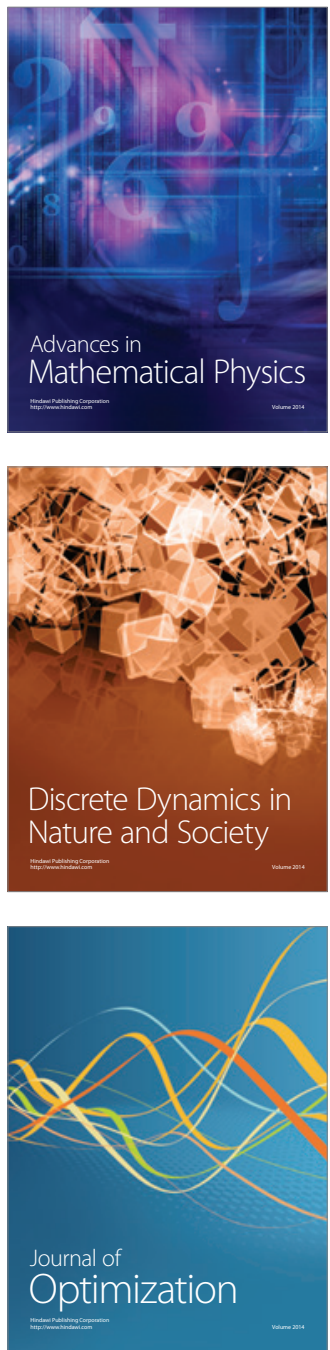